\title{
Immunohistochemistry Was Performed
}

National Cancer Institute

\section{Source}

National Cancer Institute. Immunohistochemistry Was Performed. NCI Thesaurus. Code C160383.

An indication that immunohistochemical testing was performed during the study. 